\title{
Neuropsychological assessment in patients with relapsing-remitting multiple sclerosis and mild functional impairment: correlation with magnetic resonance imaging
}

G P Anzola, L Bevilacqua, S F Cappa, R Capra, L Faglia, E Farina, G Frisoni, C Mariani, M P Pasolini, L A Vignolo

\begin{abstract}
Forty one moderately impaired patients with clinically confirmed multiple sclerosis (MS) and a relapsing-remitting course were submitted to a neuropsychological battery and magnetic resonance imaging (MRI) to correlate the neuropsychological performances with the degree of cerebral demyelination. The neuropsychological results were indicative of a very mild overall impairment. The patients were subdivided into two groups (extensive periventricular demyelination or discrete lesions on MRI) and the results of neuropsychological tests compared. Patients with extensive periventricular demyelination had an inferior performance on concept formation, non-verbal reasoning and verbal memory tests.
\end{abstract}

Magnetic Resonance Imaging (MRI) of the brain is a sensitive tool to detect demyelinating lesions in multiple sclerosis (MS). In clinically definite MS, MRI demonstrates lesions in a proportion ranging from $78 \%{ }^{1}$ to $99 \%{ }^{2}$ of cases; in suspected $\mathrm{MS}^{3}$ lesions have been found in $62 \%$ of patients.

The correlation of MRI findings with the clinical features report conflicting results. Some authors ${ }^{4-6}$ found no correlation with either the duration of illness or the disability score, while others ${ }^{78}$ reported a positive correlation between severity of MRI lesions and disability score. Moreover, recent serial studies in relapsing patients have documented changes on MRI unaccompanied by relevant new neurological symptoms or signs. ${ }^{910}$

One relevant aspect of MS disability, which has been emphasised in recent years, is neuropsychological impairment. Cognitive deficits can be found in a substantial number of MS patients ${ }^{11}$ and do not seem to be related either to length of illness or severity of the functional impairment. $^{12-14}$ Studies investigating the relationship between neuropsychological deficits and structural brain damage are scanty. Rao et $a l^{15}$ found a relationship between CTassessed ventricular enlargement and intellectual and memory dysfunction in 47 patients with chronic progressive MS. MRI has been employed by Medaer et al ${ }^{16}$ and Huber et al ${ }^{17}$ to investigate the extent of brain involvement in patients with clinically and/or psychometrically assessed dementia, with different results: in the former study patients with cognitive impairment showed an overall greater degree of demyelination, while in the latter it was only the severity of corpus callosum atrophy that differentiated the demented patients.

The aim of the present research is to investigate the relationship between MRI involvement and neuropsychological performance in a group of outpatients with relapsing-remitting, clinically definite MS and mild overall functional impairment.

\section{Material and methods \\ Patients}

Forty one subjects were selected out of the patient population attending three MS clinics, on the basis of the following criteria:

1) Clinically definite MS according to Poser's criteria. $^{18}$

2) Relapsing-remitting course.

3) Kurtzke disability score ${ }^{19}$ equal or inferior to 6 .

4) Educational level of at least five years.

5) Right-handedness (Edinburgh Inventory score $=10)^{20}$

6) Willingness to participate in the study.

The patients' characteristics are summarised in table 1.

\section{Neuropsychological battery}

The following tests were administered in the same sequence in a single session lasting approximately two hours. The patients had received no medication for at least two days before testing.

Token Test ${ }^{21}$ A sensitive test to detect auditory comprehension impairment. The score is the number of correct responses (range 0-36).

Judgment of Line Orientation ${ }^{22}$ A visuo-spatial matching task, sensitive to right hemisphere damage. The score is the number of correct responses (range 0-30).

Table 1 Patients' characteristics $(N=41)$

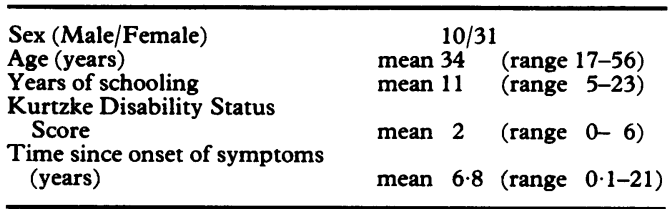


Table 2 Comparison (Mann-Whitney U-test) of demographic, clinical and neuropsychological data in patients without (Group 1) and with (Group 2) extensive periventricular demyelination. Mean (range)

\begin{tabular}{|c|c|c|c|c|}
\hline & $\begin{array}{l}\text { Group } 1 \\
(n=19)\end{array}$ & $\begin{array}{l}\text { Group 2 } \\
(n=22)\end{array}$ & $U$ & $p$ \\
\hline $\begin{array}{l}\text { Age (years) } \\
\text { Education }\end{array}$ & $32 \quad(17-56)$ & $34 \cdot 8(20-56)$ & $181 \cdot 5$ & ns \\
\hline $\begin{array}{l}\text { (years) } \\
\text { Kurtzke Score } \\
\text { Zung Score } \\
\text { Short Tale } \\
\text { Raven's PM } \\
\text { Corsi }\end{array}$ & $\begin{array}{r}12 \cdot 3(5-18) \\
2 \cdot 3(0-6) \\
42 \cdot 9(24-79) \\
15 \cdot 7(6-21) \\
32 \cdot 1(20-36)\end{array}$ & $\begin{array}{r}10 \cdot 1(5-23) \\
2 \cdot 0(0-6) \\
43 \cdot 9(24-74) \\
12 \cdot 6(4-21) \\
27 \cdot 9(12-36)\end{array}$ & $\begin{array}{l}146 \cdot 5 \\
188 \\
196 \cdot 5 \\
123 \\
112\end{array}$ & $\begin{array}{l}\text { ns } \\
\text { ns } \\
\text { ns } \\
0 \cdot 012 \\
0.005\end{array}$ \\
\hline $\begin{array}{l}\text { Supraspan } \\
\text { Weigl } \\
\text { Benton }\end{array}$ & $\begin{array}{l}10 \cdot 2(4-18) \\
12 \cdot 7(9-15) \\
22 \cdot 9(18-29)\end{array}$ & $\begin{array}{l}10 \cdot 1 \quad(3-18) \\
10 \cdot 1(0-15) \\
22 \cdot 7(10-30)\end{array}$ & $\begin{array}{l}199 \cdot 5 \\
122 \cdot 5 \\
208\end{array}$ & $\begin{array}{l}\text { ns } \\
0 \cdot 011 \\
\text { ns }\end{array}$ \\
\hline
\end{tabular}

Short Tale ${ }^{23}$ A verbal memory test similar to the "logical memory" subtest of the Wechsler Memory Scale. The score is the mean number of items recalled immediately after presentation and 10 minutes later (range 0-28).

Raven's Coloured Progressive Matrices ${ }^{24}$ A non verbal reasoning test. The score is the number of correct responses (range 0-36).

Digit Span From the Wechsler Adult Intelligence Scale, ${ }^{25}$ a verbal short term memory test. The score is the longest sequence recalled in correct order.

Corsi $S_{p a n^{25}}$ A sequential block-tapping task, which is considered the visuo-spatial equivalent of Digit Span. Score as for digit span.

Verbal Fluency ${ }^{26}$ Assessing the timed production of words after phonemic and semantic cues. The score is the total number of acceptable responses.

Corsi Supra-span ${ }^{27}$ A test of spatial non-verbal learning. The score is the number of trials to reach the criterion (three consecutive correct repetitions of an eight-block sequence) up to a maximum of eighteen trials.

Weigl Test ${ }^{28}$ A sorting test assessing concept formation as well as "set shifting" abilities.
The score reflects the number of correctly identified categories (range 0-15).

Zung Depression Rating $S c a l e^{29}$ A self-administered questionnaire.

\section{MRI study}

All the MRI examinations were performed employing a $0.5 \mathrm{~T}$ superconductive unit (Philips Gyroscan S 5), capable of performing inversion recovery (IR) and spin echo (SE) sequences. In a standard examination multiple echoes (ME) were employed: pulse sequences had a repetition time (TR) varying from 500 to $800 \mathrm{~ms}$ with an echo time (TE) from 50 to $200 \mathrm{~ms}$. Four images were usually obtained for each sequence. Pictures were acquired on 256 $\times 256$ matrix. Slice thickness varied from 6 to $8 \mathrm{~mm}$.

The routine examination consisted of axial slices from the foramen magnum up to the vertex and sagittal slices through the midline including the cervical spinal cord. Coronal slices were also frequently obtained in the pertinent position. ${ }^{5}$

All the patients had been submitted to MRI in a period from two days to six months before neuropsychological testing. Patients who had experienced new clinical symptoms or signs in the period between MRI and neuropsychological testing had a repeat MRI scan. This was carried out to improve clinical-anatomical correlation, even if it has been recently shown that MRI modifications may not be associated with clinical evidence. ${ }^{9} 10$

The MRI films were scored using the method proposed by Ormerod, ${ }^{2}$ which yields a numeric estimate of the severity of lesions in 15 discrete standardised areas of the brain. The evaluation of the MRI films was performed blindly to both the clinical conditions and the neuropsychological results for each patient.
Figure 1 ( $a$ and $b$ ) $M R I$ of a patient with multiple isolated lesions (Group 1).
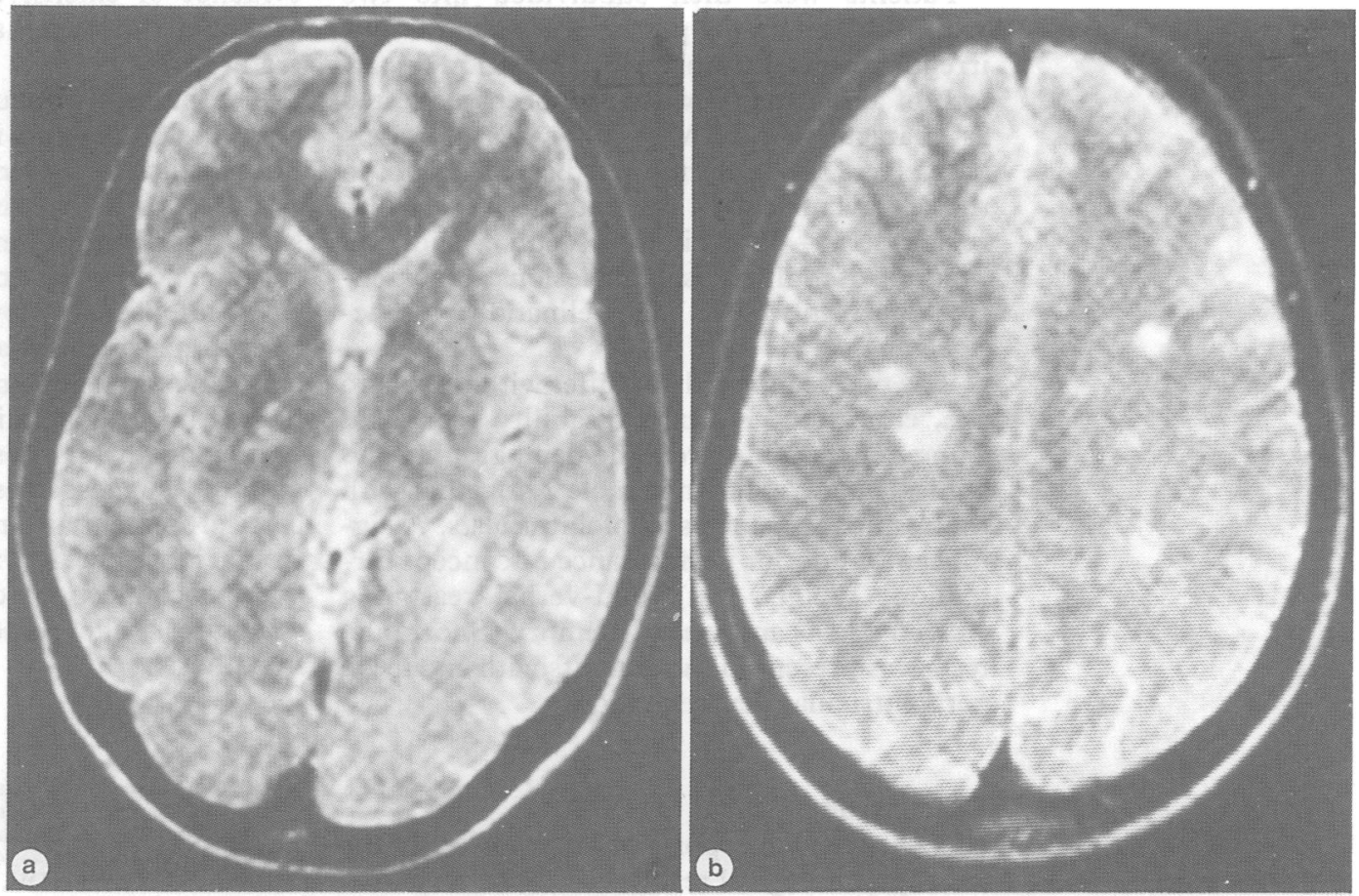
Figure 2 ( $a$ and $b$ ) $M R I$ of a patient with extensive periventricular

demyelination (Group 2).
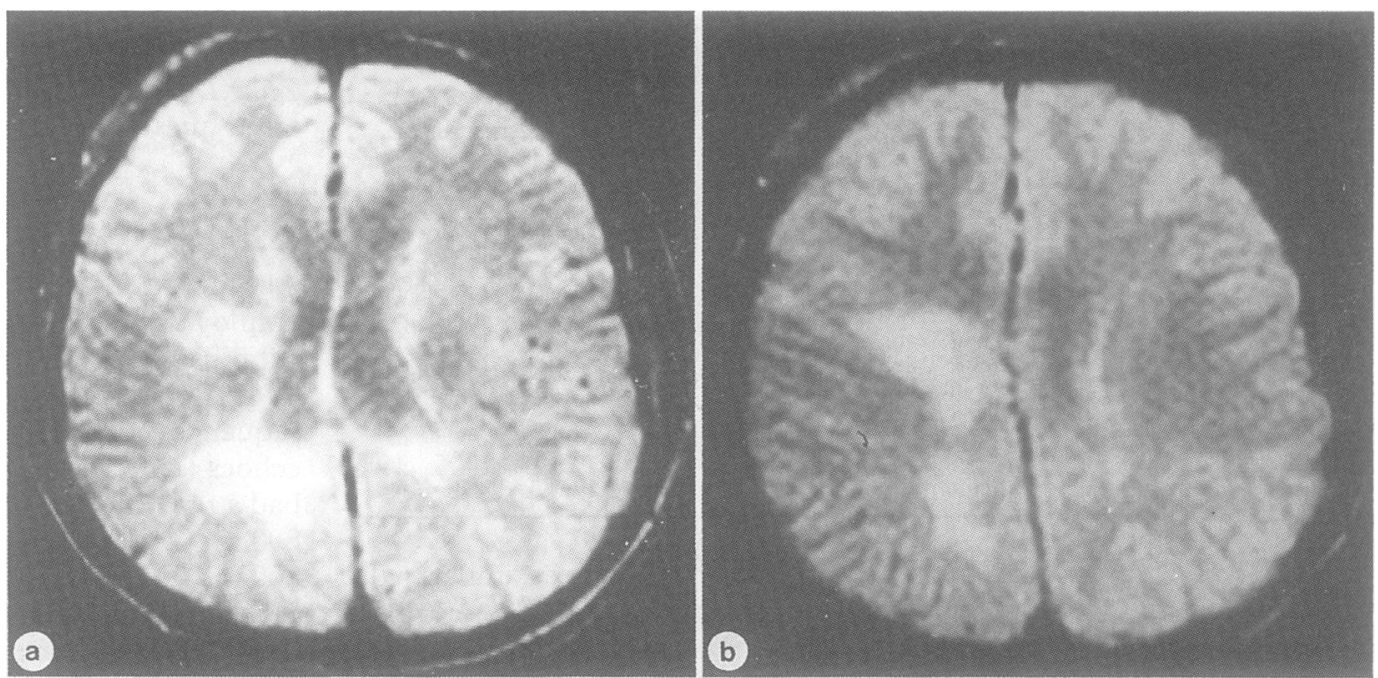

\section{Results}

The scores on neuropsychological testing of MS patients were scrutinised using published norms. ${ }^{21-28}$ Since none of the patients was impaired on the Token Test and the Digit and Corsi Span, these data were not analysed further.

Non-parametric correlations (Spearman rank correlation coefficients) were computed for the entire sample between the MRI abnormality index and scores (corrected for age, education and, when appropriate, sex) on selected tests (Raven, Weigl, Short Tale, Kurtzke disability score and Zung Depression Rating). The only significant correlation was between the severity of MRI involvement and performance on Weigl's Test $(p<0.01)$. Kurtzke and depression scores yielded no significant correlations with MRI involvement. Further correlations were attempted between severity of left or right hemispheric involvement and performances, respectively, on verbal fluency and on line orientation and supraspan spatial tests, with non significant results.

Patients were then subdivided into two groups, based on the presence of an extensive, irregular periventricular demyelination (a pattern of abnormality which has been suggested as characteristic of $M S)(N=22)$ or, alternatively, of single or multiple discrete lesions in the periventricular or extraperiventricular regions $(N=19)$. Figures 1 and 2 show an example of multiple isolated lesions and extensive periventricular demyelination respectively.

The two groups did not differ with respect to age, education, Kurtzke disability score and Zung depression score. The demographic and clinical data are shown in table 2, together with the results of neuropsychological tests. A significantly inferior performance in concept formation (Weigl's test), non-verbal reasoning (Raven's PM) and verbal memory (Short tale) tests was present in the patients with extensive periventricular demyelination.

\section{Discussion}

At variance with reports of other series ${ }^{12-14}$ the neuropsychological results showed a very mild overall impairment in our group of multiple sclerosis patients. This apparent discrepancy is probably due to the characteristics of the present patient population. The majority of previous studies included patients with a wider range of physical disability. Moreover, with a few exceptions, ${ }^{1530}$ it is often unclear whether the patients presented a chronic progressive or a relapsing-remitting course: this is particularly relevant since there is considerable evidence that cognitive dysfunction is particularly associated with a chronic/progressive disease course. ${ }^{30}{ }^{31}$ The selection of patients in the ambulatory stage (Kurtzke score equal to or less than 6) and with a relapsing-remitting course may have excluded the majority of patients with MS-related dementia. Indeed, of the 41 patients only two had been considered by the attending neurologists as cognitively impaired on clinical grounds: both showed extensive periventricular demyelination.

Nevertheless, we found an inferior performance on abstract reasoning, concept formation and verbal memory tests in patients with evidence of extensive demyelination. Visuospatial performance and language were generally spared.

The pattern of neuropsychological impairment in MS patients is similar to the so called "subcortical dementias"." This group includes patients with different conditions, such as Huntington's chorea, progressive supranuclear palsy and even Parkinson's disease: intellectual slowing, attentional problems, impairment in abstract reasoning, problem solving and memory dysfunction are the hallmarks of this clinical picture..$^{32}$ Studies, in particular from positron emission tomography, ${ }^{33}$ suggest an association between "subcortical dementia" and a deactivation of the frontal lobes, due to widespread interruption of afferent connections coming from subcortical structures. The present study supports this hypothesis.

1 Jacobs L, Kinkel WR, Polachini I, Kinkel RP. Correlation of nuclear magnetic resonance imaging with computerized tomography and clinical profiles in multiple sclerosis. Neurology 1986;36:27-34.

2 Ormerod IEC, Miller DH, McDonald WI, et al. The role of 
NMR imaging in the assessment of multiple sclerosis and isolated neurological lesions. Brain 1987;110:1579-616

3 Paty DW, Oger JJF, Kastrukoff LF, et al. MRI in the diagnosis of MS: a prospective study with comparison of clinical evaluation, evoked potentials, oligoclonal banding, and CT. Neurology 1988;38:180-5.

4 Kirshner HS, Tsai SI, Runge VM, Price AC. Magnetic resonance imaging and other techniques in the diagnosis of multiple sclerosis. Arch Neurol 1985;42:859-63.

5 Scotti G, Scialfa G, Biondi A, Landoni L, Caputo D, Cazzullo CL. Magnetic resonance in multiple sclerosis. Cazzullo CL. Magnetic resonance
Neuroradiology 1986;28:319-23.

6 Uhlenbrock D, Seidel D, Gehlen W, et al. MR imaging in multiple sclerosis: comparison with clinical, CSF, and multiple sclerosis: comparison with clinical, CSF, and
visual evoked potential findings. AJNR 1988;9:59-67.

7 Borgel F, Hommel M, Pollak P, et al. L'imagerie par resonance magnétique dans la sclérose en plaques. Rev Neurol 1986;142:6-7:598-606.

8 Stevens JC, Farlow MR, Edwards MK, Yu PI. Magnetic resonance imaging: clinical correlation in 64 patients with multiple sclerosis. Arch Neurol 1986;43:1145-8.

9 Isaac C, Li DKB, Genton M, et al. Multiple Sclerosis: a serial study using MRI in relapsing patients. Neurology 1988;38:1511-5.

10 Willoughby EW, Grochowski E, Li DKB, et al. Serial Magnetic Resonance scanning in multiple sclerosis: a second prospective study in relapsing patients. Ann second prospective
Neurol 1989;25:43-9.

11 Rao SM. Neuropsychology of multiple sclerosis: a critical review. J Clin Exp Neuropsych 1986;5:503-42.

12 Peyser JM, Edwards KR, Poser CM, Filskov SB. Cognitive functions in patients with multiple sclerosis. Arch Neurol 1980;37:577-9.

13 Lyon-Caen O, Jouvent R, Hauser S, et al. Cognitive functions in demyelinating diseases. Arch Neurol 1986; 43:1138-41.

14 Van Den Burg W, Van Zomeren AM, Minderhound JM, Prange JA, Meijer NSA. Cognitive impairment in patients with multiple sclerosis and mild physical disability. Arch Neurol 1987;44:494-501.

15 Rao SM, Glatt S, Hammeke TA, et al. Chronic progressive multiple sclerosis: relationships between cerebral ventricular size and neuropsychological impairment. Arch tricular size and neuro
Neurol $1984 ; 41: 625-31$.

16 Medaer R, Nelissen E, Appel B, Swerts M, Geutjens J, Callaert $H$. Magnetic resonance imaging and cognitive functioning in multiple sclerosis. $J$ Neurol 1987;235:86-9.

17 Humber SJ, Paulson GW, Shuttleworth EC, et al. Magnetic resonance imaging correlates of dementia in multiple sclerosis. Arch Neurol 1987;44:732-6.

18 Poser CM, Paty D, Scheinberg L, et al. New diagnostic criteria for multiple sclerosis: guidelines for research protocols. Ann Neurol 1983;13:227-31.

19 Kurtzke JF. Rating neurologic impairment in multiple sclerosis: an expanded disability status scale (EDSS). Neurology 1983;33:1444-52.

20 Oldfield RC. The assessment and analysis of handedness: the Edinburgh Inventory. Neuropsychologia 1971;9 97-113.

21 De Renzi E, Faglioni P. Normative data and screening power of a shortened version of the Token Test. Cortex 1978; 14:41-9.

22 Benton AL. Judgment of line orientation. In: Benton LA, de Hamsher K, Spreen O, eds. Contributions to neuropsychological assessment. A clinical manual. New York, Psychological assessment. A clinical manud

23 Novelli G, Papagno C, Capitani E, Laiacona M, Cappa S, Vallar $G$. Tre test clinici di memoria verbale a lungo termine. Taratura su soggetti normali. Arch Neurol Psich Psicol 1986;47:278-96.

24 Basso A, Capitani E, Laiacona M. Raven's Coloured Progressive Matrices: normative values on 305 adult normal controls. Functional Neurology 1987;2:189-94

25 Orsini A, Grossi B, Capitani E, Laiacona M, Papagno C Vallar G. Verbal and special immediate memory span. Normative data from 1355 adults and 1112 children. Italian Journal of Neurological Science 1987;8:539-48.

26 Novelli G, Papagno C, Capitani E, Laiacona M, Vallar G, Cappa S. Tre test clinici di ricerca e produzione lessicale. Taratura su soggetti normali. Arch Neurol Psich Psicol 1986;47:477-506.

27 Spinnler H, Tognoni G. Standardizzazione e taratura italiana di test neuropsicologici. The Italian Journal of Neurological Science 1987;Suppl 6:35-8.

28 De Renzi E, Faglioni P, Savoiardo M, Vignolo LA. The influence of aphasia and of the hemisphere side of the cerebral lesion in abstract thinking. Cortex 1966;2: 399-420.

29 Zung WWK. A self-rating depression scale. Arch Gen Psych 1965;12:63-70

30 Heaton RK, Nelson LM, Thompson DS, Burks JS, Franklin GM. Neuropsychological findings in relapsingremitting and chronic progressiv

31 Franklin GM, Heaton RK, Nelson LM, Filley CM, Seibert C. Correlation of neuropsychological and MRI findings in chronic/progressive multiple sclerosis. Neurology 1988; chronic/pro

32 Witehouse PJ. The concept of subcortical and cortical dementia: another look. Ann Neurol 1986;19:1-6.

33 D'Antona R, Baron JC, Samson Y, et al. Subcortical dementia. Frontal cortex hypometabolism detected by Positron Tomography in patients with progressive supranuclear palsy. Brain 1985;108:785-99. 